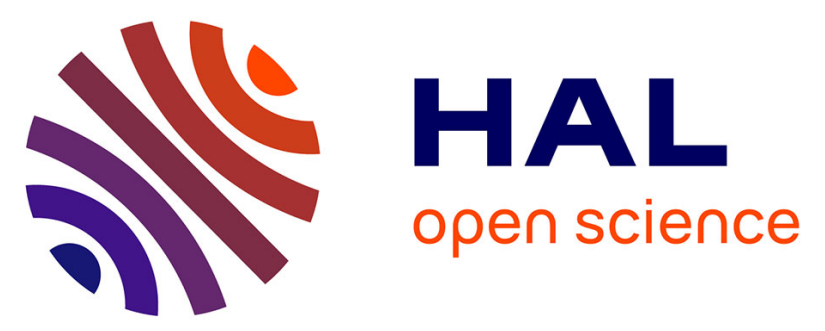

\title{
Efficient and Selective Hydrosilylation of Secondary and Tertiary Amides Catalyzed by an Iridium(III) Metallacycle: Development and Mechanistic Investigation
}

Yann Corre, Xavier Trivelli, Frédéric Capet, Jean-Pierre Djukic, Francine Agbossou-Niedercorn, Christophe Michon

\section{To cite this version:}

Yann Corre, Xavier Trivelli, Frédéric Capet, Jean-Pierre Djukic, Francine Agbossou-Niedercorn, et al.. Efficient and Selective Hydrosilylation of Secondary and Tertiary Amides Catalyzed by an Iridium(III) Metallacycle: Development and Mechanistic Investigation. ChemCatChem, 2017, 9 (11), pp.20092017. 10.1002/cctc.201700400 . hal-01715057

\section{HAL Id: hal-01715057 \\ https://hal.science/hal-01715057}

Submitted on 31 Aug 2020

HAL is a multi-disciplinary open access archive for the deposit and dissemination of scientific research documents, whether they are published or not. The documents may come from teaching and research institutions in France or abroad, or from public or private research centers.
L'archive ouverte pluridisciplinaire HAL, est destinée au dépôt et à la diffusion de documents scientifiques de niveau recherche, publiés ou non, émanant des établissements d'enseignement et de recherche français ou étrangers, des laboratoires publics ou privés. 


\title{
Efficient and selective hydrosilylation of secondary and tertiary amides using an iridium(III) metallacycle catalyst: development and mechanistic investigation.
}

\author{
Yann Corre, ${ }^{[a, b]}$ Xavier Trivelli, ${ }^{[c]}$ Frédéric Capet, ${ }^{[a]}$ Jean-Pierre Djukic, ${ }^{\left[{ }^{[d]}\right.}$ Francine Agbossou- \\ Niedercorn ${ }^{*[a, b]}$ and Christophe Michon ${ }^{*[a, b]}$
}

Dedicated to Professor Jérome Lacour at the occasion of his $50^{\text {th }}$ birthday.

\begin{abstract}
In the present study, we show accessible cationic $\operatorname{Ir}(I I I)$ metallacycles catalyse efficiently the chemoselective hydrosilylation of tertiary and secondary amides to amines. The catalyst described herein operates at low loadings using inexpensive 1,1,3,3-tetramethyldisiloxane and allows fast reactions with high yields, selectivities and turnover numbers. Whereas a transient iminium intermediate has been observed for the first time by mass spectrometry, the activations of the catalyst and the silane reagent have been studied by DFT calculations. These fundamental insights support present and future improvements of $\operatorname{Ir}(\mathrm{III})$ metallacycles through proper ligand modifications and enable further broad applications of catalysts based on metallacycles.
\end{abstract}

\section{Introduction}

Amines are ubiquitous in natural products, building blocks or targets for fine chemicals, farming-related chemicals and biologically active compounds. ${ }^{[1]}$ They can be prepared by numerous synthetic methodologies including reductive aminations, ${ }^{[1 \mathrm{c}]}$ alcohol aminations, ${ }^{[1 \mathrm{~d}]}$ hydroaminations ${ }^{[1 \mathrm{e}]}$ and transaminations..$^{[1, g]}$ However, when the preparation of more functionalised amines is required by pharmacy and fine chemistry, the reduction of amides is often preferred. Nowadays, such reaction still involves the sub-stoichiometric use of metal hydride reagents which are air and moisture sensitive and produce large amounts of waste. ${ }^{[2]}$ Whereas the reduction of amides can be performed by hydrogenation using heterogeneous catalysts under harsh conditions, the use of homogeneous catalysts allow more active and selective hydrogenation reactions by operating in milder conditions. ${ }^{[3]}$ Alternatively, the use of hydrosilanes as reductants is an area of growing interest for the mild and selective reduction of carboxylic acid derivatives by using transition metal or Lewis acid catalysts. ${ }^{[4,5]}$ Indeed, hydrosilylation, which operates without any high pressure equipment and high temperature, can be an interesting alternative to hydrogenation, provided that

[a] Dr. Y. Corre, Dr. F. Capet, Dr. F. Agbossou-Niedercorn, Dr. C. Michon, Univ. Lille, CNRS, Centrale Lille, ENSCL, Univ. Artois, UMR 8181 - UCCS - Unité de Catalyse et Chimie du Solide, F-59000 Lille, France. E-mail: christophe.michon@ensc-lille.fr, francine.agbossou@ensc-lille.fr

[b] ENSCL, UCCS-CCM-MOCAH, (Chimie-C7) CS 90108, 59652 Villeneuve d'Ascq Cedex, France

[c] Dr. X. Trivelli, UGSF CNRS, UMR 8576, Université Lille Nord de France, 59655 Villeneuve d'Ascq Cedex, France.

[d] Dr. J.-P. Djukic, Institut de Chimie de Strasbourg, UMR 7177, Université de Strasbourg, 4 rue Blaise Pascal, F-67000 Strasbourg, France.

Supporting information for this article is available on the web. inexpensive and abundant hydrosilanes are used. Because the reactivity of such reagents and related intermediates is modular and depends on the substituents of the silicon atoms, the hydrosilylation reaction can be a highly chemo- and regioselective reduction method which tolerates various other reducible functional groups. However, whereas several organometallic or organic catalysts were shown to hydrosilylate tertiary and secondary amides, ${ }^{[5]}$ the hydrosilylation of primary amides remains challenging. ${ }^{[5,1,]}$ Moreover, to the best of our knowledge, only few publications have reported effective hydrosilylation of amides by using affordable silanes and highly active catalysts operating at low loadings. ${ }^{[5 b, \mathrm{~d}, \mathrm{~h}, \mathrm{i}, \mathrm{k}]}$ Following our past studies on hydrosilylation reactions of unsaturated carboncarbon and carbon-heteroatom compounds using Ir(III) metallacycle catalysts, ${ }^{[6]}$ we report herein the first application of accessible $\operatorname{Ir}(\mathrm{III})$ metallacycles to catalyse at low loadings and high turnover numbers the hydrosilylation of secondary and tertiary amides using inexpensive 1,1,3,3-tetramethyldisiloxane.

\section{Results and Discussion}

Following our previous investigations on hydrosilylation reactions, ${ }^{6]}$ screening of $\operatorname{Ir}(\mathrm{III})$ metallacycle precursors, additives and reaction conditions was performed on the hydrosilylation of tertiary amide $\mathbf{5 a}$ (Table 1 ). In presence of 2 mol\% of trityltetra(pentafluorophenyl)borate $\left(\mathrm{Ph}_{3} \mathrm{CBArF}_{20}\right)$ and triethylsilane, chromiumtricarbonyl-bound iridacycle 2 provided a more active catalyst as compared to iridacycle 1 affording amine $6 a$ in yields of 48 versus $33 \%$ (entries 1,2 ). Addition of an $\mathrm{NMe}_{2}$ donating substituent to the chelating 2phenyl-pyridine ligand resulted overall in more active catalysts. Whereas chromiumtricarbonyl-bound iridacycle 4 led to $\mathbf{6 a}$ in a $91 \%$ yield, iridacycle 3 allowed the hydrosilylation of amide $\mathbf{5 a}$ in a nearly quantitative yield (e.g. 98\% yield) (entries 3, 4). Hence, considering the effect of the $\mathrm{Cr}(\mathrm{CO})_{3}$ moiety, a reverse trend was observed compared to iridacycle 1 and 2 . The use of $\left[\mathrm{IrCp}^{*} \mathrm{Cl}_{2}\right]_{2}$ as pre-catalyst resulted in a less efficient and selective reaction with the formation of unidentified side-products (entry 5). Changing the additive to sodium tetrakis[(3,5trifluoromethyl)phenyl]borate $\left(\mathrm{NaBArF}_{24}\right)$ or $\mathrm{N}, \mathrm{N}$ dimethylanilinium tetra(pentafluorophenyl)borate $\left(\mathrm{Me}_{2} \mathrm{PhHNBArF}_{20}\right)$ led to a significant decrease of yields (entries 6 and 7). Finally, triethylsilane was replaced by inexpensive and green hydrosilylation reagents. Whereas polymethylhydroxysiloxane (PMHS) afforded amine 6a in a lower yield (65\%), we were glad to reach a quantitative yield using 1,1,3,3-tetramethyldisiloxane (TMDS) reagent (entries 8, 9).

Interested by the results obtained in the presence of pre-catalyst 3 and TMDS, the reaction conditions were studied in more details (Table 2). We focused first on the activity of our catalytic system by changing the loadings of the pre-catalyst 3 and $\mathrm{Ph}_{3} \mathrm{CBArF}_{20}$ additive. 
Table 1. Catalytic study.

$3 \mathrm{G}=\mathrm{none}$
3
3

[a] yield measured by GC; TCE: 1,1',2,2'-tetrachloroethane. [b] $\mathrm{Ph}_{3} \mathrm{CBArF}_{20}$ : trityl tetra(pentafluorophenyl)borate. [c] with unidentified side-products. [d] NaBArF 24 : sodium tetrakis[(3,5-trifluoromethyl)phenyl]borate. [e] $\mathrm{Me}_{2} \mathrm{PhHNBArF} 20$ : N,N-Dimethylanilinium tetra(pentafluorophenyl)borate. [f] TMDS: 1,1,3,3-tetramethyldisiloxane. [g] PMHS: Polymethylhydroxysiloxane. [h] $91 \%$ yield after $45 \mathrm{~h}$ reaction.

A control experiment proved the additive was not catalysing itself the hydrosilylation of amide $\mathbf{5 a}$ (entry 1). In the presence of $1 \mathrm{~mol} \%$ of pre-catalyst 3 , quantitative yields were obtained at 100 and $80^{\circ} \mathrm{C}$ (entries 2,3 ) but a reaction at $60^{\circ} \mathrm{C}$ resulted in a significant decrease of the yield (entry 4 ). When the pre-catalyst loading was reduced from 1 to 0.5 mol\%, the yield was still quantitative at $100^{\circ} \mathrm{C}$ (entry 5), while a reaction performed at $80^{\circ} \mathrm{C}$ resulted in a $58 \%$ yield (entry 6). By operating at 0.1 mol\% loading of 3 , the yield was again quantitative within $15 \mathrm{~h}$ providing a turnover number (TON) of 1000 (entry 7). We noticed the same catalytic performances could be maintained decreasing the amount of TMDS to 2 equivalents, an excess of silane reagent still being required in order to reach a full conversion of tertiary amide $\mathbf{5 a}$ (entries 8, 9). A further decrease of the pre-catalyst loading to $0.05 \mathrm{~mol} \%$ resulted in a complete reaction within $0.5 \mathrm{~h}$ with a TON of 2000 (entry 10). Finally, the use of a 0.01 mol\% pre-catalyst loading afforded a quantitative yield with a TON of 10000 provided the reaction was run for 24 hours (entry 11). A part the decrease of the pre-catalyst loading from 1 to 0.01 mol\%, it was worth to note a higher concentration of the reaction medium had no effect on the yield or the catalyst activity. Whereas solvents like toluene, 1,4-dioxane or CPME implied much lower yields (entries 12-14), the use of anisole resulted in a $73 \%$ yield for amine 6 a with a TON of

Table 2. Screening of reaction conditions.
1460 provided the reaction was run over 24 hours (entries 15-16). Depending on the reaction time, various amounts of a possible iminium species (vide-infra) could be observed along with product $\mathbf{6 a}$ (entries 15-16)

The scope of the hydrosilylation reaction was studied with aromatic and aliphatic tertiary amides $\mathbf{5 a - v}$ (Table 3). Under the optimised conditions determined above, the corresponding amines 6a-v were obtained generally in high to quantitative yields. Substrates 5 a-e bearing only aromatic substituents were reduced smoothly and the desired products were readily recovered in 0.5 to 2 hours of reaction (entries 1-5). The hydrosilylation reaction was effectively working with heterocyclic substrates $\mathbf{5 f - g}$ (entries 6,7 ) but compounds $\mathbf{5 h - k}$ (entries 8-11) bearing alkyl cycles on whichever side of the amide required 2 to 8 hours to be reduced in good yields. If the reaction was apparently not limited by some alkyl substituents (reagents $\mathbf{5 h}, \mathrm{I}$ - entries 8,12 ), the hydrosilylation of tertiary amides $5 \mathrm{~m}-0$ bearing either bulky isopropyl groups or just an ethyl fragment required up to 48 hours to reach average to good yields (entries 13-15). The same trend was also observed for aromatic amides $5 p$ and $5 r$ bearing a fluoro or a methoxy substituent in orthoposition (entries 16, 18). Moreover, the developed catalyst allowed highly chemoselective hydrosilylation reactions tolerating other reducible functional groups like nitro, cyano and ester. If substrates $\mathbf{5 u - v}$ functionalised by an ester or a nitrile group in para-position required more time to react completely (entries 21,22 ), other para-substituted derivatives $\mathbf{5 q}$ and $\mathbf{5 s - t}$ could be reduced smoothly within 2 to 8 hours in high yields (entries 17, 19-20).

The reaction scope was further studied with the hydrosilylation of the less reactive secondary amides 7a-t (Table 4). ${ }^{[5 d, 5 m, 50]}$ To our delight, high yields of the corresponding amines 8a-t could be obtained at $100^{\circ} \mathrm{C}$ with 2 equivalents of TMDS through a simple increase of loadings of pre-catalyst 3 and trityl tetra(pentafluorophenyl)borate additive to respectively $0.5 \mathrm{~mol} \%$ and $1 \mathrm{~mol} \%$. Similar to the reduction of tertiary amides 5a-v, aromatic secondary amides $7 \mathbf{a}-\mathbf{b}$ and $\mathbf{7 d - i}$ were quickly hydrosilylated with high to quantitative yields (entries 1, 2, 4-9). As the allyl substituent of substrate $\mathbf{7 d}$ was not reduced, we confirmed again the high chemoselectivity of the catalyst developed here (entry 4). The hydrosilylation of secondary amide 7c bearing a bulky tbutyl group needed 24 hours in order to reach an average yield (entry 3). A decrease of reactivity was also observed for aromatic amide $7 \mathbf{j}$ bearing an ethyl substituent in ortho-position, 8 hours being required to obtain a good yield (entry 10). Other ortho- or para-substituted derivatives $\mathbf{7 k - n}$ could be reduced readily, like 0 -heterocyclic substrate 70 (entries 11-15). If the hydrosilylation of aliphatic secondary amides $7 p$ and $7 t$ was also straightforward (entries 16, 20), the reaction of sterically hindered substrates $7 q-s$ bearing cyclohexyl or isopropyl groups required 24 to 48 hours to reach average to good yields (entries 17-19).

In an attempt to improve our catalytic system, we prepared a new iridacyle by changing the chelating 2phenyl-pyridine ligand for a 1-phenyl isoquinoline one while keeping the $\mathrm{NMe}_{2}$ donating substituent on the phenyl group (See the Supporting Information). The resulting iridacycle 9 was first applied to the hydrosilylation of the sterically hindered tertiary amide $\mathbf{5 n}$ (Scheme 1). Though this substrate was reduced in 48 hours using pre-catalyst $\mathbf{3}$, the use of iridacycle 9 allowed us to obtain the related tertiary amine $6 \mathrm{n}$ with a $95 \%$ yield in only 8 hours. The hydrosilylation of the bulky secondary amide $7 r$ was subsequently studied (Scheme 1). 


\begin{tabular}{|c|c|c|c|c|c|c|c|c|}
\hline \multirow[b]{2}{*}{ Entry } & \multirow[b]{2}{*}{$\begin{array}{l}\text { pre-cat. } \\
\text { (mol\%) }\end{array}$} & \multirow{2}{*}{$\begin{array}{c}\mathrm{O} \\
\mathrm{N}(\mathrm{B} \\
\begin{array}{c}\mathrm{O} M \mathrm{eq} . \\
\text { (eq.) }\end{array}\end{array}$} & \multirow{2}{*}{$\begin{array}{c}+ \text { TMDS } \\
\text { y eq. } \\
\begin{array}{c}{[5 \mathrm{a}]} \\
\left(\mathrm{mmol} . \mathrm{I}^{-1}\right)\end{array}\end{array}$} & \multicolumn{2}{|c|}{$\begin{array}{c}\text { pre-cat. } 3(\mathrm{x} \text { mol } \%) \\
\mathrm{Ph}_{3} \mathrm{CBArF}_{20}(2 \times \mathrm{mol} \%) \\
\stackrel{\begin{array}{c}\text { solvent, } \mathrm{T}\left({ }^{\circ} \mathrm{C}\right), \mathrm{t}(\mathrm{h}) \\
\text { then hydrolysis }\end{array}}{\longrightarrow}\end{array}$} & $\mathrm{N}(\mathrm{Bn})$ & \multirow[b]{2}{*}{$\begin{array}{l}\text { Yield } \\
(\%)^{[a]}\end{array}$} & \multirow[b]{2}{*}{$\operatorname{TON}^{[b]}$} \\
\hline & & & & Solvent & $\begin{array}{c}\mathrm{T} \\
\left({ }^{\circ} \mathrm{C}\right)\end{array}$ & $\begin{array}{c}\text { Time } \\
\text { (h) }\end{array}$ & & \\
\hline $1^{[c]}$ & 0 & 3 & 0.077 & TCE & 100 & 15 & 0 & - \\
\hline 2 & 1 & 3 & 0.077 & $\mathrm{TCE}^{[\mathrm{d}]}$ & 100 & 15 & 100 & 100 \\
\hline 3 & 1 & 3 & 0.077 & TCE & 80 & 15 & 100 & 100 \\
\hline 4 & 1 & 3 & 0.077 & TCE & 60 & 15 & 26 & 26 \\
\hline 5 & 0.5 & 3 & 0.154 & TCE & 100 & 15 & 100 & 200 \\
\hline 6 & 0.5 & 3 & 0.154 & TCE & 80 & 15 & 58 & 116 \\
\hline 7 & 0.1 & 3 & 0.770 & TCE & 100 & 15 & 100 & 1000 \\
\hline 8 & 0.1 & 2 & 0.770 & TCE & 100 & 15 & 100 & 1000 \\
\hline 9 & 0.1 & 1 & 0.770 & TCE & 100 & 15 & 57 & 570 \\
\hline 10 & 0.05 & 2 & 1.540 & TCE & 100 & 0.5 & 100 & 2000 \\
\hline 11 & 0.01 & 2 & 3.850 & TCE & 100 & 24 & 100 & 10000 \\
\hline 12 & 0.05 & 2 & 1.540 & toluene & 100 & 2 & 17 & 340 \\
\hline 13 & 0.05 & 2 & 1.540 & 1,4-dioxane & 100 & 2 & 6 & 120 \\
\hline 14 & 0.05 & 2 & 1.540 & $\mathrm{CPME}^{[\mathrm{e}]}$ & 100 & 2 & $16^{[f]}$ & 320 \\
\hline 15 & 0.05 & 2 & 1.540 & anisole & 100 & 0.5 & $45^{[\mathrm{g}]}$ & 900 \\
\hline 16 & 0.05 & 2 & 1.540 & anisole & 100 & 24 & $73^{[\mathrm{h}]}$ & 1460 \\
\hline
\end{tabular}

Whereas the reaction was performed with a $47 \%$ yield in $24 \mathrm{~h}$ using pre-catalyst 3 , we were glad to obtain a quantitative yield of secondary amine $8 r$ in only 6 hours while applying pre-catalyst $\mathbf{9}$. In order to understand such a ligand effect on the catalyst activity, we put all our efforts into investigating the mechanism of these $\operatorname{Ir}(\mathrm{III})$ catalysed hydrosilylation reactions.

As a preliminary study regarding the possible active intermediate species involved in the catalytic process and the mechanism of such hydrosilylation reaction, we performed analyses by electrospray ionization mass spectrometry (ESIMS) in acetonitrile of the crude reaction mixture issued from the hydrosilylation of tertiary amide $5 \mathrm{a}$ at $100^{\circ} \mathrm{C}$ in 30 minutes (Table 3, entry 1 and the Supporting Information Figures S1S4). The hydrolysed tertiary amine product $6 \mathbf{a}$ was clearly identified and dechlorinated $\operatorname{Ir}(\mathrm{III})$ complex $10 \mathrm{~b}$ could be deduced through the observed cationic fragments $10 \mathbf{b}_{1}-\mathbf{b}_{3}$ combined with $\mathrm{BArF}_{20}$ anion, with or without coordination of acetonitrile which was the solvent used for the analyses (Figures S2-S4). Hence, though the reaction mixture was not quenched, the simple use of wet acetonitrile for the solvation of the mass analysis sample led to the hydrolysis of the hydrosilylated reaction product and afforded amine $\mathbf{6 a}$. In addition, the mass analysis conditions did not allow any iridium-hydride complex to be observed, probably because of the possible ionisation of such species during the analysis or because of reaction with water and air atmosphere. A further analysis by ESI-MS of the crude mixture resulting from the hydrosilylation of reagent $\mathbf{5 a}$ in anisole allowed us to observe a mixture of tertiary amine product $\mathbf{6 a}$ and iminium species $\mathbf{C}$ (Figure S1, Scheme 2). Though the latter was already suggested as a key transient intermediate in amide hydrosilylation reactions, ${ }^{[5]}$ it was, to the best of our knowledge, never evidenced before.

Regarding the reaction mechanism, a ionic hydrosilylation ${ }^{[7]}$ pathway could be presumed. However, some of us had already shown through a combination of organometallic syntheses and DFT calculations a cohesive hydridoiridium(III) $\rightarrow$ silylium donor-acceptor complex could exist. ${ }^{[8]}$ Hence, we assumed our reaction pathway could differentiate from the others ${ }^{[4,7]}$ by the activation mode of the silane. Thermochemical data inferred from singlet state gas phase DFT-D calculation (ZORA-PBE-D3(BJ)/all electron TZP basis set) provided a solid basis for establishing a reasonable mechanistic scheme (Scheme 2) of the therein reported catalysis particularly for its initiation stage. For convenience we extended our considerations to precatalysts $\mathbf{1}, 3$ and $\mathbf{9}$. The computed thermochemistry clearly suggested that the necessary dechlorination of precatalyst 3 to yield putative electron deficient cationic intermediate $10 \mathrm{~b}$ results from a reaction with an in-situ-produced form of a stabilised silylium cation generated by the reaction of the tritylium cation with the silane reagent. ${ }^{[9]}$ For instance, the reaction of $\mathrm{Et}_{3} \mathrm{SiH}$ with $\mathrm{Ph}_{3} \mathrm{C}^{+}$is expected to produce triphenylmethane and cation $\left[\mathrm{Et}_{3} \mathrm{Si}-\mathrm{H}-\mathrm{SiEt}_{3}\right]^{+}$according to Heinekey, ${ }^{\left[{ }^{9 a}\right]}$ with a Gibbs enthalpy of $-9 \mathrm{kcal} / \mathrm{mol}$ according to our DFT-D computations (Scheme 2, Scheme 3a). Worthy to note, the hypothesis of the formation of an elusive "naked" trigonal planar silylium cation $^{[10]}$ by the stoichiometric $1: 1$ reaction of the tritylium with $\mathrm{Et}_{3} \mathrm{SiH}$ was ruled out owing to its high endoergonicity $\left(\Delta \mathrm{G}_{298}=\right.$ $+17 \mathrm{kcal} / \mathrm{mol})$. The dechlorination of 3 by $\left[\mathrm{Et}_{3} \mathrm{Si}-\mathrm{H}-\mathrm{SiEt}_{3}\right]^{+}$to give intermediary $10 \mathrm{a}, \mathrm{Et}_{3} \mathrm{SiCl}$ and $\mathrm{Et}_{3} \mathrm{SiH}$ was found 
Table 3. Hydrosilylation of tertiary amides catalysed by iridacycle 3 .

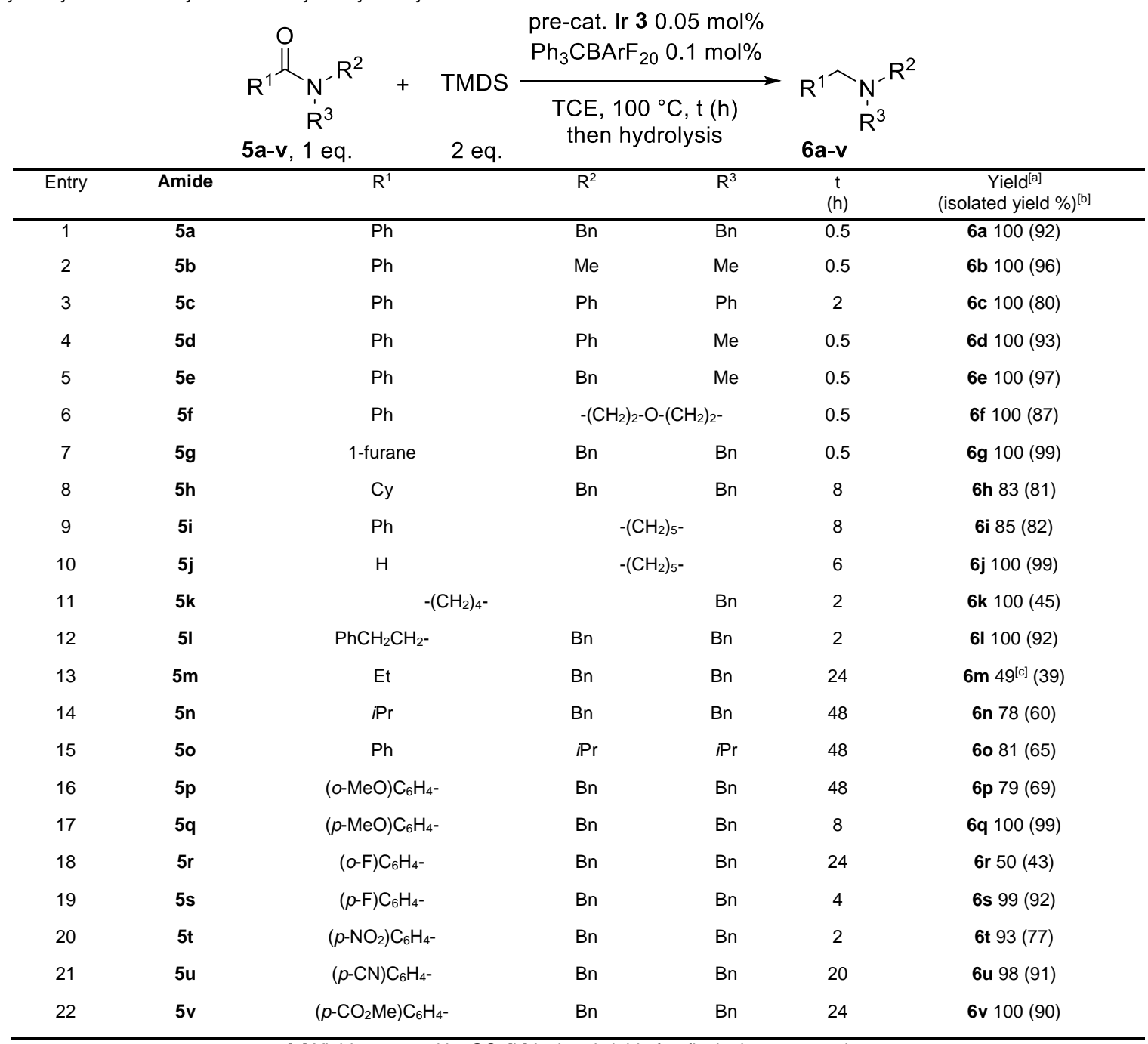

[a] Yield measured by GC. [b] Isolated yield after flash chromatography.

[c] $6 \mathrm{~m}$ along with $17 \%$ of dibenzylamine resulting from the hydrolysis of the related iminium intermediate.

in this case to be largely exoergonic with a Gibbs enthalpy of $-31 \mathrm{kcal} / \mathrm{mol}$ (Scheme 3b).

The alternative dechlorination of 3 by the tritylium was found to be endoergonic with a Gibbs enthalpy $\Delta \mathrm{G}_{298}$ of ca. +6 $\mathrm{kcal} / \mathrm{mol}$ and was therefore not considered further. The reaction of iridium catalyst $\mathbf{1 0 b}$ with $\mathrm{Et}_{3} \mathrm{SiH}$ produces the silane-iridium adduct 11b with a Gibbs enthapy of -13 $\mathrm{kcal} / \mathrm{mol}$ (Scheme 3c). ${ }^{[10,11]}$ Worthy to note here the production of 11b is by ca. $5 \mathrm{kcal} / \mathrm{mol}$ less exoergonic, that is less favorable than those of the adducts resulting from 1 and 9, i.e 11a and 11c. Still, the silylium fragment has a greater affinity for the hydrido-iridium unit in 11c than in 11a and 11b, the latter two displaying identical relative silylicity (Scheme $3 d)$. It must be pointed out here that ongoing research is focused on the mechanism of formation of intermediates 11 from 10 that will be disclosed elsewhere: preliminary results from DFT investigations point to a barrier-less process corresponding to a concerted hydride transfer and silylium trapping from $\mathrm{Et}_{3} \mathrm{Si}-\mathrm{H}$.

The term silylicity proposed here is more general than the specific TMSA (Trimethyl silyl affinity) introduced by Villinger et al. for computing thermodynamic parameters of model reaction implying the formation of molecular complexes of the trimethylsilylium cation; ${ }^{[10 a]}$ silylicity characterises in analogy with hydricity ${ }^{[11]}$ the capability of a given silyl-metal complex to release a silylium group.

The isodesmic reaction depicted in Scheme $3 d$ shows the hypothetical transfer of silylium from $11 \mathrm{~b}$ and $11 \mathrm{c}$ respectively towards $\mathbf{1 2 a}$, which is nearly isoergonic for the former pyridyl derivative and endoergonic by $\mathrm{ca} .4 \mathrm{kcal} / \mathrm{mol}$ for the latter quinoline derivative. This higher affinity of the silylium group for the hydrido-iridium unit in 11c cannot be exclusively assigned to the strong donor effect of the $\mathrm{N}, \mathrm{N}$-dimethylamino group because such an effect is not observed with 11b. We speculate that the non-coplanarity of the aryl fragments in the quinoline derivative 11c might restrict the extent of the mesomeric electron delocalisation operated by the amino group towards the quinoline group, allowing a slightly larger charge density to concentrate at the metal centre than in the pyridyl analogue 11b. which contains a planar iridacycle. A Ziegler-Rauk energy decomposition analysis (EDA) ${ }^{[12]}$ was performed on 11a, 11b and $11 \mathrm{c}$ to probe the intrinsic bonding energy of the silylium $\mathrm{Et}_{3} \mathrm{Si}^{+}$cation, or intrinsic silylicity, with the hydridoiridium fragment; it shows clearly that the interaction energy $\Delta \mathrm{E}_{\text {int }}$ of 
Table 4. Hydrosilylation of secondary amides catalysed by iridacycle 3 .

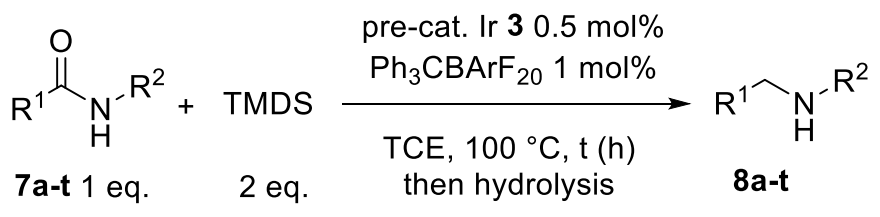

\begin{tabular}{|c|c|c|c|c|c|}
\hline Entry & Amide & $\overline{\mathrm{R}^{1}}$ & $\overline{R^{2}}$ & $\begin{array}{c}\mathrm{t} \\
\text { (h) }\end{array}$ & $\begin{array}{c}\text { Yield } \\
\text { (isolated yield \%) }\end{array}$ \\
\hline 1 & $7 a$ & $\mathrm{Ph}$ & $\mathrm{Bn}$ & 0.5 & 8a 100 (quant.) \\
\hline 2 & $7 b$ & $\mathrm{Ph}$ & $\mathrm{Me}$ & 0.5 & 8b $100(85)$ \\
\hline 3 & $7 c$ & $\mathrm{Ph}$ & $\mathrm{tBu}$ & 24 & $8 c 49$ (46) \\
\hline 4 & $7 d$ & $\mathrm{Ph}$ & allyl & 0.5 & $8 d 100(82)$ \\
\hline 5 & $7 e$ & $\mathrm{Ph}$ & $-\mathrm{CH}_{2}$-1-thiophene & 0.5 & $8 e 100(86)$ \\
\hline 6 & $7 f$ & $\mathrm{Ph}$ & cyclohexyl & 2 & $8 f 47(45)$ \\
\hline 7 & $7 g$ & $\mathrm{Ph}$ & $\mathrm{Ph}$ & 0.5 & $8 \mathrm{~g} 98$ (92) \\
\hline 8 & $7 \mathrm{~h}$ & $\mathrm{Ph}$ & $(p-\mathrm{MeO}) \mathrm{C}_{6} \mathrm{H}_{4}$ & 0.5 & 8h 100 (96) \\
\hline 9 & $7 \mathrm{i}$ & $\mathrm{Ph}$ & $(p-\mathrm{F}) \mathrm{C}_{6} \mathrm{H}_{4-}$ & 0.5 & 8i 96 (75) \\
\hline 10 & $7 \mathrm{j}$ & $\mathrm{Ph}$ & $(o-E t) \mathrm{C}_{6} \mathrm{H}_{4-}$ & 8 & 8j 83 (82) \\
\hline 11 & $7 k$ & $(o-\mathrm{MeO}) \mathrm{C}_{6} \mathrm{H}_{4-}$ & $\mathrm{Bn}$ & 2 & $8 k 94(76)$ \\
\hline 12 & 71 & $\left(p-\mathrm{MeO} \mathrm{C}_{6} \mathrm{H}_{4-}\right.$ & $\mathrm{Bn}$ & 0.5 & $8196(96)$ \\
\hline 13 & $7 m$ & $(o-F) \mathrm{C}_{6} \mathrm{H}_{4^{-}}$ & $\mathrm{Bn}$ & 0.5 & $8 \mathrm{~m} 99(86)$ \\
\hline 14 & $7 n$ & $(p-\mathrm{F}) \mathrm{C}_{6} \mathrm{H}_{4^{-}}$ & $\mathrm{Bn}$ & 0.5 & 8n 100 (quant). \\
\hline 15 & 70 & 1-furane & $\mathrm{Bn}$ & 0.5 & $80100(79)$ \\
\hline 16 & $7 p$ & $\mathrm{PhCH}_{2} \mathrm{CH}_{2^{-}}$ & $\mathrm{Bn}$ & 0.5 & 8p 100 (quant.) \\
\hline 17 & $7 q$ & cyclohexyl- & $\mathrm{Bn}$ & 24 & $8 q 68(44)$ \\
\hline 18 & $7 r$ & $\mathrm{IPr}$ & cyclohexyl & 24 & $8 r 47(40)$ \\
\hline 19 & $7 s$ & $\operatorname{Prr}$ & $\mathrm{Bn}$ & 48 & $8 \mathbf{s} 81$ (65) \\
\hline 20 & $7 t$ & \multicolumn{2}{|c|}{$-\left(\mathrm{CH}_{2}\right)_{4-}$} & 2 & 8t $100(76)$ \\
\hline
\end{tabular}

[a] Yield measured by GC. [b] Isolated yield after flash chromatography.

Scheme 1. Improved catalyst for the reduction of tertiary and secondary amides.

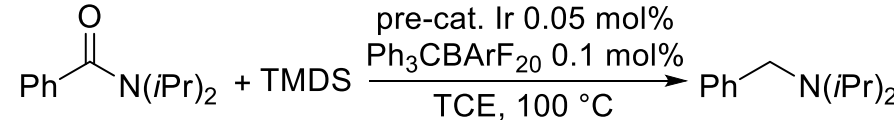

$5 n, 1$ eq.

2 eq.

then hydrolysis

pre-cat. Ir 3: $48 \mathrm{~h}, 81 \%$ yield pre-cat. Ir 9: $8 \mathrm{~h}, 95 \%$ yield

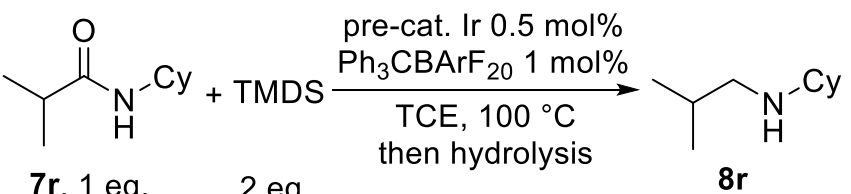

pre-cat. Ir 3: $24 \mathrm{~h}, 47 \%$ yield pre-cat. Ir 9: $6 \mathrm{~h}, 100 \%$ yield<smiles></smiles> 
Scheme 2. Proposed catalytic cycle for the reduction of tertiary and secondary amides.

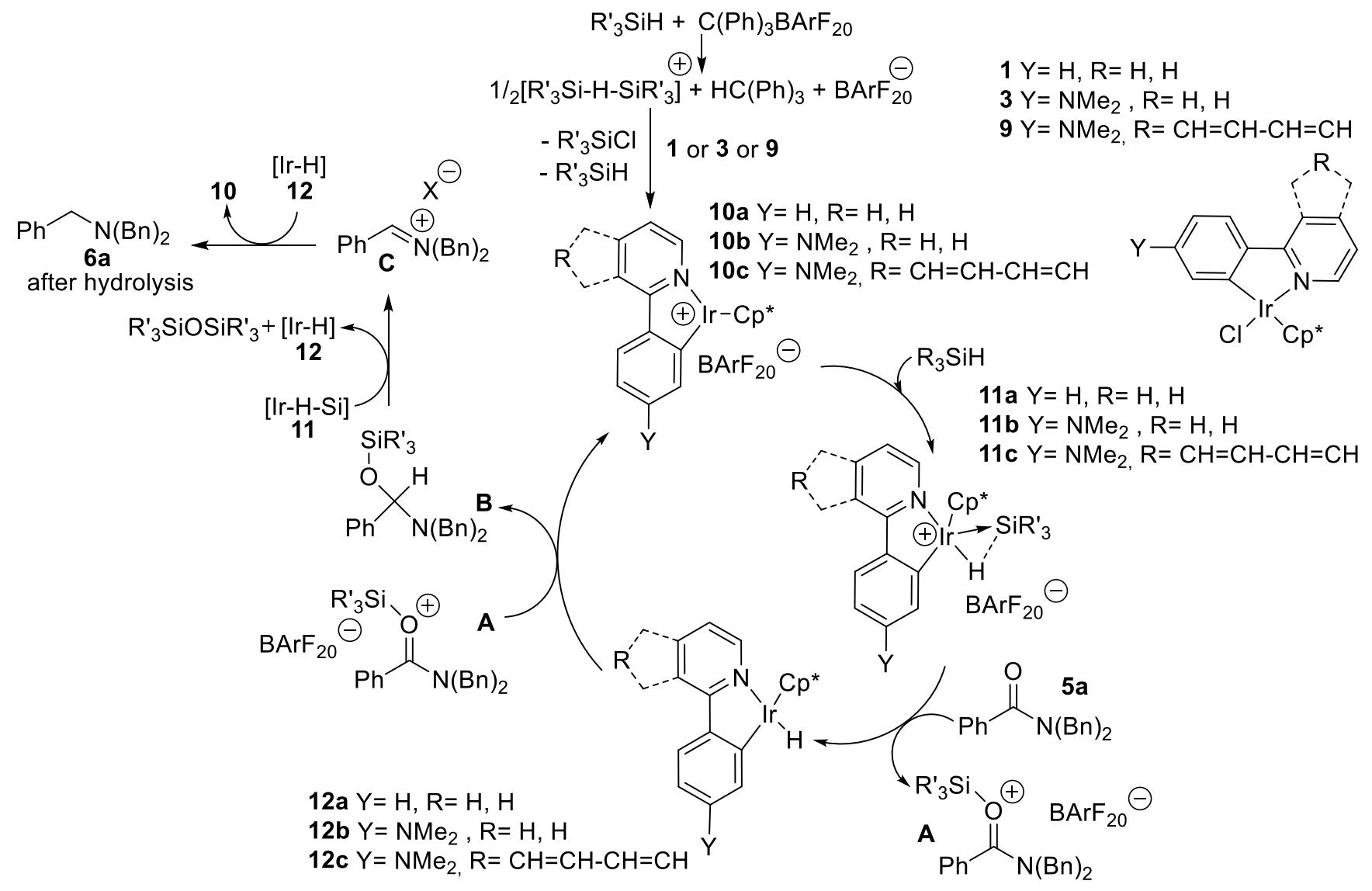

Scheme 3. Thermochemical data computed $(298.15 \mathrm{~K})$ at the ZORA-PBE$\mathrm{D} 3(\mathrm{BJ}) /$ all electron TZP level with gas phase ground state molecules devoid of counter anion $\mathrm{BArF}_{20}$.

a) Silane's conversion to a stabilised silylium

$$
\begin{array}{r}
2 \mathrm{Et}_{3} \mathrm{SiH}+\mathrm{Ph}_{3} \mathrm{C} \oplus \longrightarrow \mathrm{Ph}_{3} \mathrm{CH}+\left[\mathrm{Et}_{3} \mathrm{Si}-\mathrm{H}-\mathrm{SiEt}_{3}\right] \\
\Delta \mathrm{G}(298)=-9 \mathrm{kcal} / \mathrm{mol}
\end{array}
$$

b) De-chloridation of precatalysts

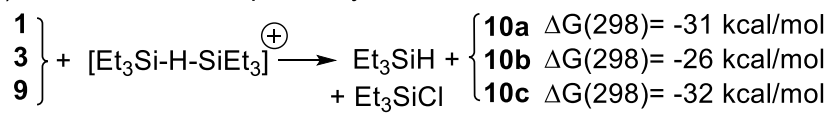

c) Addition of $\mathrm{Et}_{3} \mathrm{SiH}$ to transients $10 \mathrm{a}-\mathrm{c}$

$$
\left.\begin{array}{l}
10 a \\
10 b \\
10 c
\end{array}\right\}+E t_{3} \mathrm{SiH} \longrightarrow \begin{cases}11 \mathrm{a} & \Delta G(298)=-19 \mathrm{kcal} / \mathrm{mol} \\
11 \mathrm{~b} & \Delta \mathrm{G}(298)=-13 \mathrm{kcal} / \mathrm{mol} \\
11 \mathrm{c} & \Delta \mathrm{G}(298)=-17 \mathrm{kcal} / \mathrm{mol}\end{cases}
$$

d) Isodesmic silylium transfer reaction

(evaluation of the relative silylicity of $11 \mathrm{a}$ and $11 \mathrm{c}$ )

$$
\left.\begin{array}{l}
11 \mathrm{~b} \\
11 \mathrm{c}
\end{array}\right\}+12 \mathrm{a} \longrightarrow 11 \mathrm{a}+\left\{\begin{array}{l}
12 \mathrm{~b} \Delta \mathrm{G}(298)=0 \mathrm{kcal} / \mathrm{mol} \\
12 \mathrm{c} \Delta \mathrm{G}(298)=+4 \mathrm{kcal} / \mathrm{mol}
\end{array}\right.
$$

e) Hydride transfer to tritylium (evaluation of the hydricity of 12a-c)

$$
\left.\begin{array}{l}
12 \mathrm{a} \\
12 \mathrm{~b} \\
12 \mathrm{c}
\end{array}\right\}+\mathrm{Ph}_{3} \mathrm{C} \oplus \longrightarrow \mathrm{Ph}_{3} \mathrm{CH}+\left\{\begin{array}{l}
10 \mathrm{a} \Delta \mathrm{G}(298)=-21 \mathrm{kcal} / \mathrm{mol} \\
10 \mathrm{~b} \Delta \mathrm{G}(298)=-26 \mathrm{kcal} / \mathrm{mol} \\
10 \mathrm{c} \Delta \mathrm{G}(298)=-27 \mathrm{kcal} / \mathrm{mol}
\end{array}\right.
$$

the silylium group with the neutral hydrido-iridium fragment is by ca. $8 \mathrm{kcal} / \mathrm{mol}$ stronger in $11 \mathrm{~b}\left(\Delta \mathrm{E}_{\mathrm{int}}=-127 \mathrm{kcal} / \mathrm{mol}\right)$ and in 11c $\left(\Delta \mathrm{E}_{\mathrm{int}}=-127 \mathrm{kcal} / \mathrm{mol}\right)$ than in 11a $\left(\Delta \mathrm{E}_{\mathrm{int}}=-119\right.$ $\mathrm{kcal} / \mathrm{mol}$ ). Consistently the total natural charge (Natural Population Analysis) borne by the $\mathrm{Et}_{3} \mathrm{Si}$ group in 11a ( $\mathrm{q}=$ $+0.29)$ is slightly higher than that in $\mathbf{1 1 b}(q=+0.25)$ for example.

In the framework of the mechanism depicted in Scheme 2, adducts 11a-c are sources of hydrido-iridium intermediates $\mathbf{1 2 a - c}$ and silylium cation $\mathrm{R}_{3} \mathrm{Si}^{+} \cdot{ }^{[9,10,13]}$ The latter may activate the carbonyl group of amide substrate 5a and generate silyloxy carbonium species $\mathbf{A}$. Reaction with a first equivalent of the iridium hydride complex 12 affords silyl hemiacetal $\mathbf{B}$ along with the cationic iridium complex 10. At this stage, elimination of a silyloxide fragment may be helped by any electrophilic species present in the medium to lead to the iminium intermediate C. The latter can then react with a second equivalent of the iridium hydride complex 12 and affords the amine product 6a along with the cationic iridium catalytic species 10 (Scheme 2). As mentioned in Table 2 (entries 8, 9), 2 equivalents of TMDS were added in order to get a quantitative hydrosilylation of amide 5a. At the end of reaction, we could isolate the silicon residue from the resulting crude mixture. Interestingly, a ${ }^{1} \mathrm{H}$ NMR analysis revealed the presence of a hydride silicon species and suggested only one hydride from the two of TMDS reagent may participate to the reaction (see the Supporting Information Figures S5, S6). Further characterisation by ESI-MS of such a silicon residue formed at the end of reaction showed several silicon compounds were formed during the catalysis (Figure S7). 


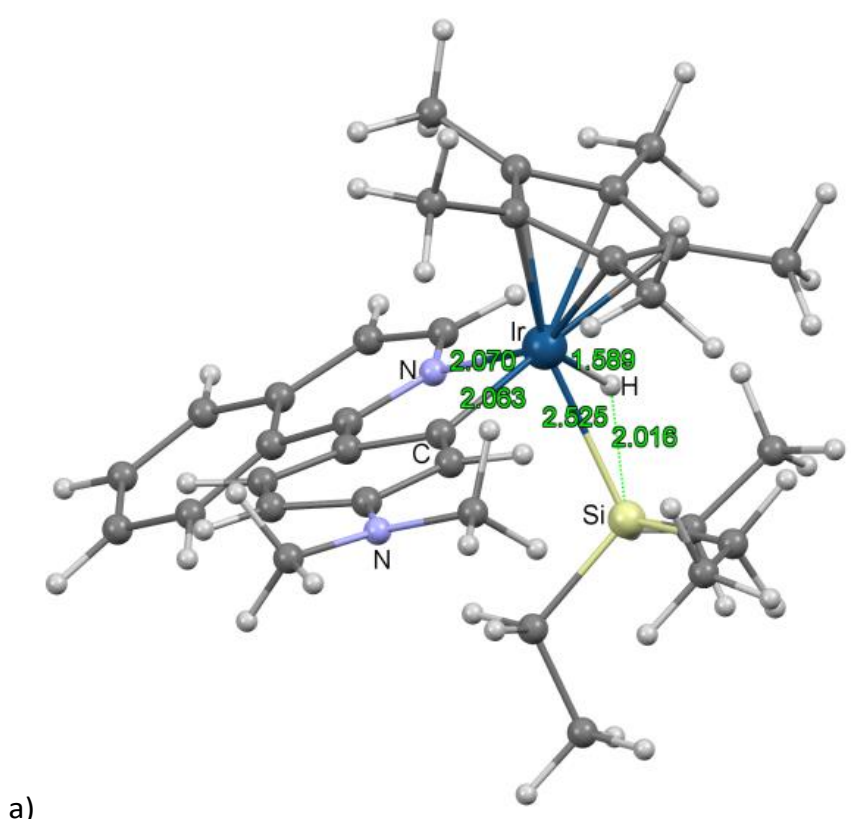

a)

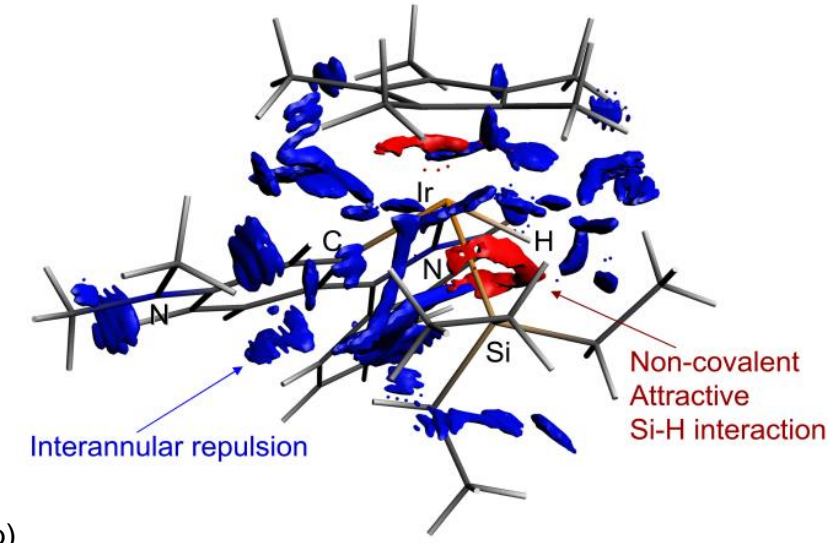

b)

Figure 1. a) Gas phase singlet state geometry of 11c optimised at the ZORA-PBE-D3(BJ)/all electron TZP level (interatomic distances printed in green are expressed in $\AA$ ); b) Similarly to $11 b$ the $\mathrm{NCl}$ plot $^{[14]}$ of $11 \mathrm{c}$ depicts a rather non-covalent attractive $\mathrm{H}$...Si interaction in this computed model were covalent and donor acceptor interactions are

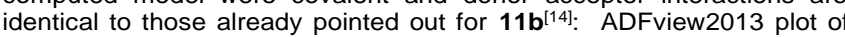
non-covalent interaction ( $\mathrm{NCl}$ ) regions (ZORA-PBE-D3(BJ)/ae-TZP) materialised by reduced density gradient isosurfaces (cut-off value $S=$ 0.02 a.u., $\rho=0.05$ a.u.) colored according to the sign of the signed density $\lambda_{2} \rho$, that is red (attractive) and blue (Pauli repulsive or nonbonded van der Waals) isosurfaces are associated with negatively and positively signed terms respectively.

Addressing the difference in reactivity of the two amino-substituted precatalysts $\mathbf{3}$ and $\mathbf{9}$ as compared to $\mathbf{1}$ is a difficult task in such a catalysis where a great number of species like substrate and cocatalysts coexist. Nevertheless, even though further efforts will be needed in the future, thermochemistry of possible reactions can be calculated by DFT computations and offer sufficient clues to attempt a rationalisation. At this stage, assuming the reactions to be mostly driven by favourable initiation and catalytic event under thermodynamic control, we can only elaborate on four points of crucial importance that are the readiness of: 1) the precatalyst's dechlorination, 2) the reaction of silane with transient 10 to give 11,3 ) silylium abstraction from 11, and 4) the hydride transfer from the hydrido-Ir transient.
Point 1: all three pre-catalysts 1, 3 and 9 can be dechlorinated readily, with a somewhat larger exoergonicity for 3 and $\mathbf{9}$ (Scheme 3b).

Point 2: 10a gives less exo-ergonically a silane-iridium adduct than 10c (Scheme 3c); this rather counter-intuitive result can be explained by the major inter-annular tensions that exist within $10 \mathrm{c}$ and which are somewhat released upon return of the Ir(III) center to a hepta- or hexacoordinate geometry like in $11 \mathrm{c}$ and $12 \mathrm{c}$ respectively (Figure 1). According to the X-ray structure determination, it is worth to note inter-annular tensions are also observed for chlorinated pre-catalyst 9 (Figure S8).

Point 3: 11a and 11b have nearly the same relative silylicity $(\Delta \mathrm{G}=0 \mathrm{kcal} / \mathrm{mol}$, Scheme $3 \mathrm{~d})$ whereas 11c displays a lower one $(\Delta \mathrm{G}=+4 \mathrm{kcal} / \mathrm{mol}$, Scheme $3 \mathrm{~d}$ and Figure 1)

Point 4: both 12a and 12c display similar hydricity (Scheme $3 e$ and Figure 1).

It seems therefore tempting to state that the outstanding performance of 9 could be related to the easier formation of silane-iridium adduct $11 \mathrm{c}$ combined with its relatively lower silylicity and to a relatively higher hydricity of its related hydrido complex 12c. A high hydricity is intuitively related to a faster reduction of an electrophile of reference. A slightly lower relative intrinsic silylicity might sensibly contribute in decreasing the weight of the pathway detrimental to the catalysis that entails the formation of catalytically inactive $\mu$-hydrido bridged bis-iridium species. It was shown that such species are formed almost unavoidably in rather large amounts when a cationic solvato-iridacycle derived from 2-phenylpyridine is treated with $\mathrm{Et}_{3} \mathrm{SiH}$ at room temperature. ${ }^{[8]}$

\section{Conclusions}

To summarise, we have described a highly efficient catalytic process for the hydrosilylation of tertiary and secondary amides. The combination of an accessible $\operatorname{Ir}(\mathrm{III})$ metallacycle complex and trityltetra(pentafluorophenyl)borate in the presence of $1,1,3,3$ tetramethyldisiloxane allowed, at low loadings, the chemoselective reduction of a large array of amide substrates in high yields and turnover numbers tolerating a wide range of substituents. According DFT calculations, silane-iridium adduct is a source of hydrido-iridium intermediate and silylium cation. The latter activates the carbonyl group of the amide substrate and generates a silyloxy carbonium species. Reaction with a first equivalent of the iridium hydride complex affords silyl hemiacetal along with the cationic catalytic species. The further elimination of silyloxide fragment leads to an iminium intermediate which has been observed my mass spectrometry for the first time. Reaction with a second equivalent of the iridium hydride complex affords the amine product along with the cationic catalytic species. On the whole, the work described herein demonstrates the reactivity of $\operatorname{Ir}(\mathrm{III})$ metallacycles can be improved through proper ligand modifications to allow the straightforward catalytic hydrosilylation of challenging amide substrates. Such developments foresee clearly future broad and significant applications of catalysts based on metallacycles. 


\section{Experimental Section}

\section{General Procedure for the catalysis}

In a Schlenk tube, amide reagent $(1.54 \mathrm{mmol}, 1$ eq.) and iridium (III) catalyst (0.05 mol\%, 0.0005 eq.) are introduced. BArF salt $(0.1 \mathrm{~mol} \%)$ is then added in a glovebox. Under nitrogen, $1 \mathrm{~mL}$ of TCE and TMDS (2 eq.) are transferred by syringe and the reaction mixture is heated at $100{ }^{\circ} \mathrm{C}$ under stirring for 2 hours (the Schlenk tube being closed under N2). Afterwards, the solvent is evaporated under vacuum (using a Schlenk line) and the reaction mixture is hydrolysed following method $A$ or $B$.

Method A: acid hydrolysis (examples: hydrosilylation of amines $5 \mathrm{a}, 5 \mathrm{~b}, 5 \mathrm{e}, 5 \mathrm{f}, 5 \mathrm{~g}$ ). After complete evaporation of the solvent, the reaction mixture is diluted with diethylether $(4 \mathrm{~mL})$ and $\mathrm{HCl} 4 \mathrm{M}(4 \mathrm{~mL})$ is added. The resulting solution is stirred vigorously during 10 minutes to afford the protonated amine as a precipitate which was recovered by filtration and washed with diethylether. The resulting solid was then disolved in $\mathrm{CH}_{2} \mathrm{Cl}_{2}$ and neutralized with an aqueous solution of $\mathrm{NaOH} 1 \mathrm{M}$ (for tertiary amines) or of saturated $\mathrm{NaHCO}_{3}$ (for secondary amines) until $\mathrm{pH}>7$. After extraction ( 3 times with $\mathrm{CH}_{2} \mathrm{Cl}_{2}$ ), the organic phase was dried with $\mathrm{MgSO}_{4}$ and evaporated to afford the desired amine.

Method B: basic hydrolysis (examples: hydrosilylation of amines 5c, 5d). After complete evaporation of the solvent, the reaction mixture is diluted with methanol $(4 \mathrm{~mL})$ and $\mathrm{NaOH} 1 \mathrm{M}(4 \mathrm{~mL})$ is added. After extraction (3 times with $\mathrm{Et}_{2} \mathrm{O}$ ), the organic phase was dried with $\mathrm{MgSO}_{4}$ and evaporated to afford the desired amine which was further purified by flash chromatography using mixtures of petroleum ether and ethyl acetate with $5 \% \mathrm{NEt}_{3}$.

\section{Computational details}

Computations were performed with methods of Density Functional Theory, i.e the PBE ${ }^{[15]}$ GGA functional implemented in the Amsterdam Density Functional package (ADF2013 ${ }^{[16]}$ version) and augmented with Grimme's DFT-D3(BJ) ${ }^{[17]}$ implementation of dispersion with a Becke-Johnson (BJ) damping function. Scalar relativistic corrections with the Zeroth Order Regular Approximation ${ }^{[18]}$ were applied with ad hoc allelectron (AE) basis sets consisting of polarised triple- $\zeta$ (TZP) Slater type orbitals. Geometry optimisation by energy gradient minimisation was carried out in all cases with a numerical grid accuracy comprised between 4.5 and 8 , an energy gradient convergence criterion of $10^{-3}$ au and a very tight SCF convergence criterion. Vibrational modes were computed to verify that the optimised geometries were related to energy minima not considering residual modes comprised between 0 and $100 \mathrm{i} \mathrm{cm}^{-1}$. Fragment interaction energies were extracted from a conventional Energy Decomposition Analysis according to the Ziegler-Rauk method implemented in ADF. ${ }^{[11]}$ By extension, intinsic hydricity and silylicity have been determined by considering the disruption of a hydrido-metal and silyl-metal intermediate by confering to the hydrogen a negative charge (hydride) and to the silyl fragment a positive charge (silylium in its prepared geometry). This arbitrary choice of fragmentation, although artificial, gives an intuitive direct access to the intrinsic affinity of the metal center for those ligands that are suspected to play a central role in the catalysis depicted here according to a recent report. ${ }^{[8]}$

\section{Acknowledgements}

The University of Lille 1 and Région Hauts-de-France are acknowledged for PhD fellowship (Y. C.). The CNRS, the Chevreul Institute (FR 2638), the Ministère de l'Enseignement Supérieur et de la Recherche, the LABEX Chimie des Systèmes Complexes (Strasbourg), the Région Hauts-de-France and the FEDER are acknowledged for supporting and funding partially this work. Mrs Catherine Méliet (UCCS) is thanked for elemental analyses. Mrs Céline Delabre (UCCS) is thanked for GC and GC-MS analyses. Mrs Nathalie Duhal and Céline Lenglart (CUMA, Univ. of Lille) are thanked for HRMS analyses. Ms Thi Nguyet Anh Ho (ENSCL) and Ms Catrina Larisa Georgiana (Erasmus exchange between ENSCL, France and University of Craiova, Romania) are thanked for their help with experimental work.

Keywords: iridium $\bullet$ metallacycles $\bullet$ hydrosilylation $\bullet$ amides $•$ amines.

[1] a) K. S. Hayes, Appl. Catal. A: Gen. 2001, 221, 187; b) S. A. Lawrence Amines: Synthesis, Properties and Applications 34 (Cambridge University Press, 2004); c) A. F. Abdel-Magid, S. J. Mehrman, Org Process Res. Dev. 2006, 10, 971; d) Q. Yang, Q. Wang, Z. Yu, Chem. Soc. Rev. 2015, 44, 2305; e) L. Huang, M. Arndt, K. Gooßen, H. Heydt, L. J. Gooßen, Chem. Rev. 2015, 115, 2596; f) M. Breuer, K. Ditrich, T. Habicher, B. Hauer, M. Keßeler, R. Stürmer, T. Zelinski, Angew. Chem. 2004, 116, 806; Angew. Chem. Int. Ed. 2004, 43, 788; g) M. D. Truppo, J. D. Rozzell, N. J. Turner, Org. Process Res. Dev. 2010, 14, 234.

[2] a) G. W. Gribble, Chem. Soc. Rev. 1998, 27, 395; (b) J. Seyden-Penne, Reductions by the Alumino- and Borohydrides in Organic Synthesis, (2nd ed.; Wiley: New York, 1997).

[3] a) Catalysed hydrogenation of amides to amines: a) S. Das, S. Zhou, D. Addis, S. Enthaler, K. Junge, M. Beller, Top. Catal. 2010, 53, 979; b) P. A. Dub, T. Ikariya, ACS Catal. 2012, 2, 1718; c) S. Werkmeister, K. Junge, M. Beller, Org. Process Res. Dev. 2014, 18, 289 and references therein; d) T. vom Stein, M. Meuresch, D. Limper, M. Schmitz, M. Hölscher, J. Coetzee, D. J. Cole-Hamilton, J. Klankermayer, W. Leitner, J. Am. Chem. Soc. 2014, 136, 13217; e) E. Balaraman, D. Milstein, Topics in Organomet. Chem. 2015, 48, 19; f) J. M. John, R. Loorthuraja, E. Antoniuk, S. H. Bergens, Catal. Sci. Technol. 2015, 5, 1181; g) J. R. Cabrero-Antonino, E. Alberico, K. Junge, H. Junge, M. Beller, Chem. Sci. 2016, 7, 3432; h) J. A. Garg, S. Chakraborty, Y. Ben-David, D. Milstein, Chem. Commun. 2016, 52, 5285; i) J. R. Cabrero-Antonino, E. Alberico, H. J. Drexler, W. Baumann, K. Junge, H. Junge, M. Beller, ACS Catalysis 2016, 6, 47; j) M. L. Yuan, J. H. Xie, S. F. Zhu, Q. L. Zhou, ACS Catalysis 2016, 6, 3665; k) M. L. Yuan, J. H. Xie, Q. L. Zhou, ChemCatChem 2016, 8, 3036.

[4] a) B. Marciniec, H. Maciejewski, C. Pietraszuk, P. Pawluć, in Hydrosilylation: A Comprehensive Review on Recent Advances, (Ed. B. Marciniec, Springer, Heidelberg, 2009); b) D. Addis, S. Das, K. Junge, M. Beller, Angew. Chem. 2011, 123, 6128; Angew. Chem. Int. Ed. 2011, 50, 6004; c) K. Revunova, G. I. Nikonov, Dalton Trans. 2015, 44, 840; d) J. Pesti, G. L. Larson, Org. Process Res. Dev. 2016, 20, 1164; e) M. Oestreich, Angew. Chem. 2016, 128, 504, Angew. Chem. Int. Ed. 2016, 55, 494; f) M. C. Lipke, A. L. Liberman-Martin, T. D. Tilley, Angew. Chem. 2017, 129, 2298; Angew. Chem. Int. Ed. 2017, 56, 2260.

[5] Catalysed hydrosilylation of amides to amines: a) Y. Motoyama, K. Mitsui, T. Ishida, H. Nagashima, J. Am. Chem. Soc. 2005, 127, 13150; b) S. Hanada, E. Tsutsumi, Y. Motoyama, H. Nagashima, J. Am. Chem. Soc. 2009, 131, 15032; c) Y. Sunada, H. Kawakami, T. Imaoka, Y. Motoyama, H. Nagashima, Angew. Chem. 2009, 121, 9675; Angew. Chem. Int. Ed. 2009, 48, 9511; d) Y. Motoyama, M. Aoki, N. Takaoka, 
R. Aoto, H. Nagashima, Chem. Commun. 2009, 45, 1574; e) S. Zhou, K Junge, D. Addis, S. Das, M. Beller, Angew. Chem. 2009, 121, 9671 Angew. Chem. Int. Ed. 2009, 48, 9507; f) S. Das, D. Addis, S. Zhou, K Junge, M. Beller, J. Am. Chem. Soc. 2010, 132, 1770; g) S. Das, D. Addis, K. Junge, M. Beller, Chem. Eur. J. 2011, 17, 12186; h) S. Park M. Brookhart, J. Am. Chem. Soc. 2012, 134, 640; i) C. Cheng, M. Brookhart, J. Am. Chem. Soc. 2012, 134, 11304; j) Y. Li, J. A. Molina de La Torre, K. Grabow, U. Bentrup, K. Junge, S. Zhou, A. Brückner, M. Beller, Angew. Chem. 2013, 125, 11791; Angew. Chem. Int. Ed. 2013 52, 11577; k) T. Dombray, C. Helleu, C. Darcel, J.-B. Sortais, Adv Synth. Catal. 2013, 355, 3358; I) E. Blondiaux, T. Cantat, Chem Commun. 2014, 50, 9349; m) O. O. Kovalenko, A. Volkov, H. Adolfsson, Org. Lett. 2015, 17, 446; n) S. Das, Y. Li, L.-Q. Lu, K. Junge, M. Beller, Chem. Eur. J. 2016, 22, 7050;0) B. Li, J.-B. Sortais, C. Darcel, RSC Advances 2016, 6, 57603; p) F. Tinnis, A. Volkov, T. Slagbrand, H. Adolfsson, Angew. Chem. 2016, 128, 4638; Angew. Chem. Int. Ed. 2016, 55, 4562; q) A. Augurusa, M. Mehta, M. Perez, J. Zhu, D. W Stephan, Chem. Commun. 2016, 52, 12195.

[6] a) W. Iali, F. La Paglia, X.-F. Le Goff, D. Sredojevic, M. Pfeffer, J.-P. Djukic, Chem. Commun. 2012, 48, 10310; b) Y. Corre, W. Iali, M. Hamdaoui, X. Trivelli, J.-P. Djukic, F. Agbossou-Niedercorn, C. Michon, Catal. Sci. Technol. 2015, 5, 1452; c) C. Michon, K. MacIntyre, Y. Corre F. Agbossou-Niedercorn, ChemCatChem 2016, 8, 1755; d) Y. Corre, C Werlé, L. Brelot-Karmazin, J.-P. Djukic, F. Agbossou-Niedercorn, C Michon, J. Mol. Catal. A: Chem. 2016, 423, 256; e) Y. Corre, V. Rysak F. Capet, J.-P. Djukic, F. Agbossou-Niedercorn, C. Michon, Chem. Eur. J. 2016, 22, 14036.

[7] a) M. Oestreich, J. Hermeke, J. Mohr, Chem. Soc. Rev. 2015, 44, 2202; b) M. Iglesias, F. J. Fernández-Alvarez, L. A. Oro, ChemCatChem 2014 6, 2486; c) T. T. Metsänen, P. Hrobárik, H. F. T. Klare, M. Kaupp, M. Oestreich, J. Am. Chem. Soc. 2014, 136, 6912; d) W. Wang, P. Gu, Y Wang, H. Wei, Organometallics 2014, 33, 847; e) M. Iglesias, P. J. Sanz-Miguel, V. Polo, F. J. Fernández-Alvarez, J. J. Pérez-Torrente, L. A. Oro, Chem. Eur. J. 2013, 19, 17559; f) O. G. Shirobokov, L. Kuzmina,
G. I. Nikonov, J. Am. Chem. Soc. 2011, 133, 6487; g) J. Yang, P. S White, M. Brookhart, J. Am. Chem. Soc. 2008, 130, 17509; h) R. M Bullock, Chem. Eur. J. 2004, 10, 2366.

[8] M. Hamdaoui, M. Ney, V. Sarda, L. Karmazin, C. Bailly, N. Sieffert, S Dohm, A. Hansen, S. Grimme. J.-P. Djukic, Organometallics 2016, 35, 2207

[9] a) S. J. Connelly, W. Kaminsky, D. M. Heinekey, Organometallics 2013 32, 7478; b) M. Nava, C. A. Reed, Organometallics 2011, 30, 4798; c) S. P. Hoffmann, T. Kato, F. S. Tham, C. A. Reed, Chem. Commun 2006, 767.

[10] a) M. F. Ibad, P. Langer, A. Schulz, A. Villinger, J. Am. Chem. Soc. 2011, 133, 21016; b) C. A. Reed, Acc. Chem. Res. 1998, 31, 325.

[11] E. S. Wiedner, M. B. Chambers, C. L. Pitman, R. M. Bullock, A. J.-M. Miller, A. M. Appel, Chem. Rev. 2016, 116, 8655.

[12] T. Ziegler, A. Rauk, Inorg. Chem. 1979, 18, 1755.

[13] a) C. Scheeren, F. Maasarani, A. Hijazi, J.-P. Djukic, M. Pfeffer, S. D. Zaric, X.-F. LeGoff, L. Ricard, Organometallics 2007, 26, 3336; b) Y. Hu, L. Li, A. P. Shaw, J. R. Norton, W. Sattler, Y. Rong, Organometallics 2012, 31, 5058.

[14] a) J. Contreras-Garcia, E. R. Johnson, S. Keinan, R. Chaudret, J. P. Piquemal, D. N. Beratan, W. Yang, J. Chem. Theor. Comput. 2011, 7, 625; b) E. Johnson, S. Keinan, P. Mori-Sanchez, J. Contreras-Garcia, A. J. Cohen, W. Yang, J. Am. Chem. Soc. 2010, 132, 6498.

[15] J. P. Perdew, K. Burke, M. Ernzerhof, Phys. Rev. Lett. 1996, 77, 3865.

[16] K. Vanka, M. S. W. Chan, C. C. Pye, T. Ziegler, Organometallics 2000 $19,1841$.

[17] a) S. Grimme, S. Ehrlich, L. Goerigk, J. Comp. Chem. 2011, 32, 1456; b) S. Grimme, Wiley Interdisciplinary Reviews: Computational Molecular Science 2011, 1, 211.

[18] a) E. van Lenthe, E.-J. Baerends, J. G. Snijders, J. Chem. Phys. 1993, 99, 4597; b) E. van Lenthe, E.-J. Baerends, J. G. Snijders, J. Chem Phys. 1994, 101, 9783; c) E. van Lenthe, A. Ehlers, E.-J. Baerends, J. Chem. Phys. 1999, 110, 8943. 
